\title{
Resarch Paper: Prognostic Factors of In-Hospital Mortality in Adult Patients With Aluminum Phosphide (ALP) Poisoning in Southern Iran (2014-2018)
}

\author{
Mahdi Alibeigi ${ }^{1,2}$ (D), Razieh Sadat Mousavi-Roknabadi², ${ }^{2 *}$ (D), Najmeh Ahmadzadeh Goli ${ }^{4}$, Mehrdad Sharifi,3 (iD, Faramarz Farahmand ${ }^{1}$ (iD)
}

1. Department of Emergency Medicine, School of Medicine, Shiraz University of Medical Sciences, Shiraz, Iran.

2. Department of Medical Toxicology, Imam Reza Hospital, Mashhad University of Medical Sciences, Mashhad, Iran.

3. Emergency Medicine Research Center, Shiraz University of Medical Sciences, Shiraz, Iran.

4. Department of Internal Medicine, School of Medicine, Shiraz University of Medical Sciences, Shiraz, Iran.

\begin{tabular}{|c|c|}
\hline $\begin{array}{l}\text { Use your device to scan } \\
\text { and read the article online }\end{array}$ & dtation Alibeigi M, Sadat Mousavi-Roknabadi R, Ahmadzadeh Goli N, Sharifi M, Farahmand F. Prognostic Factors of In- \\
\hline 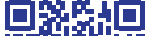 & Hospital Mortality in Adult Patients With Aluminum Phosphide (ALP) Poisoning in Southern Iran (2014-2018). International \\
\hline $28+4 y^{2}$ & Journal of Medical Toxicology and Forensic Medicine. 2021; 11(4):34976. https://doi.org/10.32598/ijmtfm.v11i4.34976 \\
\hline 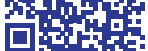 & doil'https://doi.org/10.32598/ijmtfm.v11i4.34976 \\
\hline
\end{tabular}

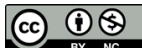

Article info:

Received: 23 May 2021

First Revision: 08 Jun 2021

Accepted: 22 Jun 2021

Published: 21 Dec 2021

\section{A B S T RACT}

Background: The suicide with aluminum phosphide, known as rice tablet, has increased significantly. This study aimed to investigate the epidemiology of Aluminum Phosphide (ALP) poisoning and determine the in-hospital mortality prognostic factors in adult people referring to ALP poisoning to one of the main poisoning centers in southern Iran.

Methods: This retrospective cross-sectional study (March 21, 2014, to March 21, 2018) was conducted on all adult patients ( $>16$ years) with ALP poisoning who were referred to Ali-Asghar Hospital (affiliated with Shiraz University of Medical Sciences). All data were extracted from the patients' medical files. The patients were categorized into two groups of survived and nonsurvived. Univariate and multivariate logistic regression analyses were conducted to determine prognostic factors for in-hospital mortality, and Odds Ratios (ORs) were reported.

Results: Totally, 97 patients were enrolled in this study. The patients' Mean \pm SD age was $29.3 \pm 12.2$ years. Both study groups (survived and non-survived) were matched in most demographic and poisoning characteristics. Nausea $(62.9 \%)$ and vomiting $(49.5 \%)$ were the most symptoms at the time of admission. Castor oil (66\%), N-acetyl cysteine (56.7\%), and magnesium sulfate $(52.6 \%)$ were the most frequent treatment in these patients. The multivariate analysis showed that age $(\mathrm{OR}=1.12,95 \% \mathrm{CI}$ : $1.03-1.22)$, body temperature ( $\mathrm{OR}=0.02,95 \% \mathrm{CI}: 0.01-0.48)$, resistant acidosis $(\mathrm{OR}=77.10,95 \% \mathrm{CI}: 5.05-1176.86)$, and taking sodium bicarbonate ( $\mathrm{OR}=12.35,95 \% \mathrm{CI}$ : $1.25-122.10)$ were the prognostic factors of in-hospital mortality.

Conclusion: The in-hospital mortality rate in patients with ALP poisoning was $29.9 \%$. Age, illiteracy, body temperature, resistant acidosis, and taking sodium bicarbonate were the prognostic factors of in-hospital mortality in these patients.

\section{* Corresponding Author:}

Razieh Sadat Mousavi-Roknabadi, MD.

Address: Department of Emergency, School of Medicine, Shiraz University of Medical Sciences, Shiraz, Iran.

Tel: +98 (913) 1563018

E-mail: mousavi razieh@sums.ac.ir 


\section{Introduction}

oisoning is one of the most important causes of morbidity and mortality $\mathbf{P}$ worldwide, making it a public health issue, especially in developing countries [1-3]. Rice tablet, with its Aluminum Phosphide (ALP) chemical formula, is an inorganic substance used as an insecticide and rodenticide in rice and grain warehouses $[4,5]$. ALP poisoning causes many symptoms [6]. Upon contact with water or acid, ALP produces phosphine, ammonia, and carbon dioxide. The produced phosphine gas is rapidly absorbed and causes shock, marked electrolyte disturbances, and multifunctional dysfunction via several complex processes leading to oxidative stress and the inhibition of multiple vital enzymes [4].

The clinical effects of this toxin vary depending on acute or chronic contact. Symptoms usually occur within a few hours and may progress during the first 24 hours. Local effects on the gastrointestinal system include epigastric pain, vomiting, diarrhea, and abdominal pain. Multiple organ failure, which presents with acute heart failure, shock, Acute Respiratory Distress Syndrome (ARDS), and renal and hepatic failure, can rapidly lead to death. Cerebral effects such as seizures and coma usually occur only in severely poisoned patients. Direct cardiotoxicity in combination with acidosis and marked electrolyte disturbances in ions such as potassium, calcium, and magnesium lead to arrhythmia, which is a common complication and is often associated with fatal outcomes. Later, atrial or ventricular bradyarrhythmia and tachyarrhythmias may develop [7-9]. Various studies have suggested several treatments to save these patients' lives; however, currently, there are no specific treatments. Most of them are supportive, and some controversies exist on their indications [10-13].

Today, the use of rice tablets to perpetrate suicide has increased significantly, and several studies have been conducted on the epidemiology of ALP poisoning in the world, as well as in Iran [14-17]. In European countries, unlike Asian countries, ALP is only accessible to certain people, so suicide with ALP is uncommon [18]. After India, Iran has the highest mortality rate due to rice tablet poisoning, with more than 700 cases of annual death [19]. The use of ALP in Iran is particularly common in rice breeding areas. Several reports have shown the high incidence of either intentional or accidental poisoning with this substance every year, partly due to the household usage of rice tablets, making it available to the public $[3,14]$. The prevalence of ALP poisoning is increasing, ranking the second or third cause of poisoning in many communities and regions, and its mortality has been reported to be $30 \%-100 \%$ [1, 20-22].

To our knowledge, there is no similar study on the epidemiology of ALP poisoning in the Fars Province of Iran in these years. Hence, the current study aimed to investigate the epidemiology of this condition and determining the in-hospital mortality prognostic factors in adult ALP poisoned patients referring to one of the main poisoning centers in southern Iran.

\section{Materials and Methods}

\section{Study design and patients}

This retrospective cross-sectional study (March 21, 2014, to March 21, 2018) was conducted on all medical files of adult patients ( $>16$ years) with ALP poisoning, who were referred to Ali-Asghar Hospital (affiliated with Shiraz University of Medical Sciences), one of the primary poisoning centers in the south of Iran. Patients with missing or uncompleted medical files were excluded from the study.

The diagnosis of ALP poisoning had been made based on history taken from the patient or his/her relatives. A clinical toxicologist also visited the patients and provided further information to establish the diagnosis based on clinical signs and symptoms such as hypotension, respiration pattern, and feeling thirsty at the time of admission. All data were extracted from the patients' medical files and collected in a data-gathering form, which included two parts: a) demographic information (age, gender, marital status, the place of living, etc.); b) clinical and laboratory findings at the time of admission, as well as the patients' treatments and outcomes.

\section{Definitions}

Level of consciousness: It was categorized into 2 levels: conscious and unconscious (including clouding of consciousness, lethargy, obtundation, stupor, and coma) [23].

Hypotension: It is a decrease in blood pressure below accepted low values (usually less than $90 \mathrm{mmHg}$ ) [24].

Resistant acidosis: It is defined as the condition that a patient with severe acidosis received several doses of sodium bicarbonate, but acidosis persists [25]. 
Acute Kidney Injury (AKI): It is s a sudden episode of kidney failure or kidney damage that happens within a few hours or a few days [26].

\section{Statistical analysis}

All analyses were performed in SPSS version 16.0 for Windows. The Shapiro-Wilk t test was used to check the normal distribution of numerical variables. Independent sample t or Mann-Whitney U tests were used for two-group comparisons of continuous variables. The Chi-square and Fisher exact tests were used for proportions. In the univariate logistic regression analysis, each variable was separately entered. Variables with a $P$ value less than 0.2 from the univariate analysis were entered into the multivariate logistic regression analysis, using the forward stepwise methods to determine prognostic factors for in-hospital mortality, and then the Odds Ratios (OR) were reported. Results were presented as Mean \pm SD for continuous variables and number (percentage) for categorical ones. Two-sided P-values of less than 0.05 and Confidence Interval (CI) of $95 \%$ were considered statistically significant.

\section{Results}

A total of 97 patients were enrolled in this study. The patients' Mean \pm SD age was $29.3 \pm 12.2$ years (range: 1670 years; $30.7 \pm 11.8$ years in men vs $27.5 \pm 12.7$ years in women; $\mathrm{P}=0.2)$. Also, 54 (55.7\%) were men $(\mathrm{P}=0.10)$. It was found that $45.5 \%$ and $34 \%$ of poisoned patients were in the age groups of 16-24 and 25-34 years, respectively. All patients $(100 \%)$ had committed suicide attempts. Most patients were living in urban areas $(\mathrm{P}<0.0001)$ and were literate $(\mathrm{P}<0.0001)$. Thirty patients $(30.9 \%)$ had comorbidity, and $41(42.3 \%)$ had a psychiatric disease (such as depression or positive history of suicide attempts). Twenty-nine patients $(29.9 \%)$ died. The patients were categorized into two groups (survivors and non-survivors), and they were compared. As shown in Table 1, the non-survived patients had higher Mean $\pm \mathrm{SD}$ age $(\mathrm{P}=0.02)$ and a higher frequency of illiteracy $(\mathrm{P}<0.001)$. But, both groups were the same in other demographic characteristics.

Table 1 was the most common pharmaceutical form of ALP, and most of the poisoning occurred at night. Also, 29 patients (29.9\%) were admitted to Intensive Care Unit (ICU) admission, with no difference between survived and non-survived patients. Also, both groups were similar in poisoning characteristics, such as the pharmaceutical form of ALP poisoning, the season of poisoning, time of the poisoning, length of hospital stay, and ICU admission (Table 2).
As shown in Table 3, Systolic and Diastolic Blood Pressures (SBP and DBP) at the time of admission, as well as body temperature, were lower in non-survived patients. Still, the Respiratory Rate (RR) was higher in survivors. Peripheral $\mathrm{O}_{2}$ saturation $<92 \%(\mathrm{P}=0.002)$ and Glasgow Coma Scale (GCS) $<14$ were seen more in non-survived patients $(\mathrm{P}=0.001)$. Nausea $(62.9 \%)$ and vomiting $(49.5 \%)$ were the most symptoms at the time of admission. All signs and symptoms at the time of admission were the same in both groups, except abnormal pupils, which was more common in non-survivors $(\mathrm{P}=0.03)$, as well as lower $\mathrm{PH}(\mathrm{P}<0.001)$ and $\mathrm{HCO}_{3}(\mathrm{P}<0.001)$. During the hospitalization, resistant acidosis $(\mathrm{P}<0.001)$, hypotension $(\mathrm{P}<0.001)$, and Acute Renal Failure (ARF) $(\mathrm{P}=0.03)$ were more common in non-survivors.

Castor oil (66\%), N-acetyl Cysteine (NAC) (56.7\%), and magnesium sulfate $\left(\mathrm{MgSO}_{4}\right)(52.6 \%)$ were the most frequent treatments in the patients with ALP poisoning. But, sodium bicarbonate $\left(\mathrm{NaHCO}_{3}\right)(\mathrm{P}=0.008)$, epinephrine $(\mathrm{P}=0.001)$, dopamine $(\mathrm{P}=0.02)$, and atropine $(\mathrm{P}=0.03)$ were used more in non-survived patients (Table 4).

The univariate analysis found that in-hospital mortality had a statistically significant relationship with age, gender, education, GCS, abnormal pupil, resistant acidosis, hypotension, ARF, SBP, DBP, respiratory rate, temperature, $\mathrm{HCO}_{3}$, and taking sodium bicarbonate $\left(\mathrm{NaHCO}_{3}\right)$ (Table 5).

The multivariate analysis showed that age $(\beta=0.12$, $\mathrm{OR}=1.12,95 \% \mathrm{CI}: 1.03-1.22)$, body temperature $(\beta=$ 3.76, $\mathrm{OR}=0.02,95 \% \mathrm{CI}=0.01-0.48)$, resistant acidosis $(\beta=4.35, \quad \mathrm{OR}=77.10,95 \% \mathrm{CI} ; 5.05-1176.86)$, taking sodium bicarbonate $\left(\mathrm{NaHCaO}_{3}\right) \quad(\beta=2.51, \mathrm{OR}=12.35$, 95\% CI: $1.25-122.10)$ were the main important prognostic factors of in-hospital mortality in patients with ALP poisoning (Table 6).

\section{Discussion}

The present study showed that in-hospital mortality rate in patients with ALP poisoning was $29.9 \%$. Montazer et al. reported a mortality rate of $32 \%$ for ALP poisoning [27]. In a study by Christophers et al. in India, the mortality rate was reported $66.6 \%$ in ALP poisoned patients [28]. This rate was obtained $58.6 \%$ in a study by Rahbar Taramsary et al. [29] and 62.5\% in Mazandaran Province of Iran [30]. Hosseinian et al. and Shadnia et al. reported mortality rates of $18.6 \%$ and $31 \%$, respectively $[31,32]$. In a study in Pakistan, this rate was reported as $78 \%$ [33]. Overall, the mortality rate of ALP poisoning in the present study seems to be lower than the rates 
Table 1. Patients' demographic characteristics

\begin{tabular}{|c|c|c|c|c|c|}
\hline \multirow{2}{*}{\multicolumn{2}{|c|}{ Variables }} & \multicolumn{3}{|c|}{ Mean \pm SD/No.(\%) } & \multirow{2}{*}{$\mathbf{P}$} \\
\hline & & \multirow{2}{*}{$\begin{array}{c}\text { Survivors }(\mathbf{n}=\mathbf{6 8}) \\
27.2 \pm 10.9\end{array}$} & \multirow{2}{*}{$\begin{array}{c}\text { Non-survivors }(\mathbf{n}=\mathbf{2 9}) \\
34.3 \pm 13.9\end{array}$} & \multirow{2}{*}{$\begin{array}{c}\text { Total }(\mathbf{n}=97) \\
29.3 \pm 12.2\end{array}$} & \\
\hline & & & & & $0.02^{*}$ \\
\hline \multirow{6}{*}{ Age groups (y) } & $16-24$ & $34(50.0)$ & $10(34.5)$ & $44(45.5)$ & \multirow{6}{*}{0.08} \\
\hline & $25-34$ & $23(33.8)$ & $10(34.5)$ & $33(34.0)$ & \\
\hline & $35-44$ & $7(10.3)$ & $2(6.9)$ & $9(9.3)$ & \\
\hline & $45-54$ & $2(2.9)$ & $4(13.8)$ & $6(6.2)$ & \\
\hline & $55-64$ & $1(1.5)$ & $3(10.3)$ & $4(4.1)$ & \\
\hline & $65-74$ & $1(1.5)$ & $0(0)$ & $1(1.0)$ & \\
\hline \multirow{3}{*}{ Gender } & Men & $33(48.5)$ & $21(72.4)$ & $54(55.9)$ & \multirow{3}{*}{$0.04^{*}$} \\
\hline & Women & $35(51.5)$ & $8(27.6)$ & $43(44.3)$ & \\
\hline & P-value & - & - & 0.10 & \\
\hline \multirow{3}{*}{ Marital status } & Single & $35(52.2)$ & $12(44.4)$ & $46(47.4)$ & \multirow{3}{*}{0.65} \\
\hline & Married & $31(47.8)$ & $15(55.6)$ & $47(48.5)$ & \\
\hline & $\mathrm{P}$ & - & - & 0.88 & \\
\hline \multirow{3}{*}{ Place of living } & Urban & $62(91.2)$ & $25(86.2)$ & $87(89.7)$ & \multirow{3}{*}{0.48} \\
\hline & Rural & $6(8.8)$ & $4(13.8)$ & 10(10.3) & \\
\hline & $P$ & - & - & $<0.0001^{*}$ & \\
\hline \multirow{3}{*}{ Education } & Literate & $66(97.1)$ & $22(75.9)$ & $88(90.7)$ & \multirow{3}{*}{$<0.001^{*}$} \\
\hline & Illiterate & $2(2.9)$ & $7(24.1)$ & $9(9.3)$ & \\
\hline & $P$ & - & - & $<0.0001^{*}$ & \\
\hline \multirow{3}{*}{$\begin{array}{l}\text { Having a comor- } \\
\text { bidity }\end{array}$} & Yes & $24(35.3)$ & $6(20.7)$ & $30(30.9)$ & \multirow{3}{*}{0.23} \\
\hline & No & $44(64.7)$ & $23(79.3)$ & $67(69.1)$ & \\
\hline & $P$ & - & - & $<0.0001^{*}$ & \\
\hline \multirow{3}{*}{$\begin{array}{l}\text { Having psychiatric } \\
\text { disease }\end{array}$} & Yes & $32(47.1)$ & $9(31.0)$ & $41(42.3)$ & \multirow{3}{*}{0.18} \\
\hline & No & $36(52.9)$ & $20(69.0)$ & $56(57.7)$ & \\
\hline & $P$ & - & - & $0.03^{*}$ & \\
\hline
\end{tabular}

* Statistically significant; SD: Standard Deviation

International Journal of
Medical Toxicology \& Forensic Medicine

reported in most other similar studies. Nevertheless, conducting larger studies is recommended.

The average age of the patients with ALP poisoning in this study was 29.3 years, higher in non-survivors. It was found that $45.5 \%$ and $34 \%$ of poisoned patients were in the age groups of 16-24 and 25-34 years, respectively. Khodabandeh et al. reported that the highest prevalence of ALP poisoning was in the age group of 15-24 years (48.6\%) [34], and in Shadnia et al.'s study, most patients were between 20 and 40 years old [32]. Rahbar Taramsary et al. also found that $64.7 \%$ of patients were in the age group of 15-30 years, with a mean age of 29 years [29]. Moreover, Navabi et al. reported that the average age of surviving and non-survived from ALP poisoning was 28.7 and 31.3 years [3]. Similar to their study, we found that higher age was related to higher in-hospital mortality. Also, we found that age was a prognostic factor for in-hospital mortality.

Given that most patients are young, various problems during this period and failure to overcome them may encourage these individuals to suicide. To determine the prevalence of this phenomenon in each age group, however, it is better to interpret the observed mortality rate according to the population pyramid. It is noteworthy that all patients in the present study had intentionally used ALP for suicide, which was in line with the recent study's 
Table 2. Patients' poisoning characteristics

\begin{tabular}{|c|c|c|c|c|c|}
\hline \multirow{2}{*}{ Variables } & & \multicolumn{3}{|c|}{ Mean $\pm S D / N o .(\%)$} & \multirow[b]{2}{*}{$\mathbf{P}$} \\
\hline & & $\begin{array}{l}\text { Survivors } \\
(n=68)\end{array}$ & $\begin{array}{c}\text { Non-Survivors } \\
(n=29)\end{array}$ & $\begin{array}{c}\text { Total } \\
(n=97)\end{array}$ & \\
\hline \multirow{3}{*}{ Pharmaceutical form } & Tablet & $56(82.4)$ & 28(96.6) & $84(86.6)$ & \multirow{3}{*}{0.18} \\
\hline & Powder & $6(8.8)$ & $1(3.4)$ & $7(7.2)$ & \\
\hline & Inhalation & $6(8.8)$ & $0(0)$ & $6(6.2)$ & \\
\hline \multirow{2}{*}{$\begin{array}{l}\text { Concomitant use with another } \\
\text { drug }\end{array}$} & Yes & $9(13.2)$ & $4(13.8)$ & $13(13.4)$ & \multirow{2}{*}{0.99} \\
\hline & No & $59(86.8)$ & $25(86.2)$ & $84(86.6)$ & \\
\hline \multirow{2}{*}{ How poisoning occurs } & Collective & $3(4.4)$ & $0(0)$ & $3(3.1)$ & \multirow{2}{*}{0.55} \\
\hline & Individual & $65(95.60$ & $29(100)$ & $94(96.9)$ & \\
\hline \multirow{4}{*}{ Season of poisoning } & Spring & $16(23.5)$ & $4(13.8)$ & $20(20.6)$ & \multirow{4}{*}{0.72} \\
\hline & Summer & $16(23.5)$ & $9(31.0)$ & $25(25.8)$ & \\
\hline & Fall & $17(25.0)$ & $8(27.6)$ & $25(25.8)$ & \\
\hline & Winter & $19(27.9)$ & $8(27.6)$ & $27(27.8)$ & \\
\hline \multirow{4}{*}{ Time of poisoning } & Morning & $12(17.6)$ & $7(24.1)$ & 19(19.6) & \multirow{4}{*}{0.62} \\
\hline & Noon & $2(2.9)$ & $2(6.9)$ & $4(4.1)$ & \\
\hline & Evening & $22(32.4)$ & $9(31.0)$ & $31(32.0)$ & \\
\hline & Night & $32(47.1)$ & $11(37.9)$ & $43(44.3)$ & \\
\hline \multicolumn{2}{|c|}{ The time between consumption and hospital adm } & $4.2 \pm 5.1$ & $3.2 \pm 2.3$ & $3.9 \pm 4.4$ & 0.23 \\
\hline \multicolumn{2}{|c|}{ Length of stay (h) } & $45.7 \pm 62.9$ & $35.0 \pm 40.3$ & $42.1 \pm 57.0$ & 0.43 \\
\hline \multicolumn{2}{|c|}{ ICU admission } & $16(23.5)$ & $13(44.8)$ & 29(29.9) & 0.05 \\
\hline
\end{tabular}

findings, a phenomenon that should be taken into consideration by health policymakers $[3,4,6,29,34,35]$.

Also, the present study results showed that $55.7 \%$ of our patients were men, but there was no significant difference between the survivor and non-survivors regarding gender distribution. Similar to our results, Khodabandeh et al. found that $60.6 \%$ of ALP poisoned patients were men [34]. Shokrzadeh et al. also reported that death due to ALP poisoning was more common in men [5], a finding that was also reported by Navabi et al. [3], Saha et al. [36], Ranga et al. [37], and Rahbar Taramsary et al. [29]. This finding is justified as the rice tablet is more accessible to men because of their more engagement in agricultural activities. But, Fayaz, Montazer, et al., EtemadiAleagha et al., Taghaddosi Nejad et al., and Louriz et al. reported that most ALP poisoned patients were women $[14,27,38-40]$. It is also noteworthy that although women commit suicide about 3-5 times more than men, men have more successful suicides. However, more comprehensive studies are needed to shed light on this issue [41].
In this study, we observed that the incidence of poisoning was significantly higher in urban residents, but there was no significant difference regarding marital status. In line with our findings, Yaghoobi and Shafipour studied 716 adolescents aged 12-20 years old between 2007 and 2008 who committed suicide and found that $54.4 \%$ of them were urban residents, and more than $85 \%$ of them were single [42]. Montazer et al. also found that the prevalence of poisoning in the urban residents was about twice as high as the dwellers of rural residents [27]. In the study of Rahbar Taramsary et al., 57.9\% of ALP poisoning cases were urban residents [29], while this rate was $62.5 \%$ in the study of Yaghoobi and Shafipour [42]. Since the agricultural profession is more common among rural residents, rice tablets (as pesticides) are more readily available. So, it is expected that ALP poisoning is more prevalent among these populations. However, the higher incidence of ALP poisoning in urban areas could be due to factors such as the socio-economic status of these communities. Also, a higher rate of environmental stressors in the cities and, on the other 
Table 3. Patients' medical findings

\begin{tabular}{|c|c|c|c|c|c|}
\hline & \multirow{2}{*}{ Variables } & \multicolumn{3}{|c|}{ Mean士SD/No.(\%) } & \multirow{2}{*}{$\mathbf{P}$} \\
\hline & & $\begin{array}{l}\text { Survivors } \\
(n=68)\end{array}$ & $\begin{array}{l}\text { Non-survi- } \\
\text { vors }(n=29)\end{array}$ & $\begin{array}{l}\text { Total } \\
(n=97)\end{array}$ & \\
\hline \multirow{5}{*}{$\begin{array}{l}\text { Vital signs at the time of } \\
\text { admission }\end{array}$} & Systolic blood pressure (mmHg) & $116.2 \pm 20.2$ & $93.1 \pm 19.2$ & $110.15 \pm 22.31$ & $<0.001^{*}$ \\
\hline & Diastolic blood pressure (mmHg) & $73.2 \pm 15.0$ & $59.2 \pm 12.2$ & $69.51 \pm 21.64$ & $<0.001^{*}$ \\
\hline & Pulse rate (per minute) & $92.9 \pm 17.7$ & $85.5 \pm 29.7$ & $90.94 \pm 21.64$ & 0.25 \\
\hline & Respiratory rate (per minute) & $18.5 \pm 2.4$ & $20.3 \pm 3.1$ & $18.98 \pm 2.70$ & $<0.001^{*}$ \\
\hline & Temperature $\left({ }^{\circ} \mathrm{C}\right)$ & $37.0 \pm 0.3$ & $36.7 \pm 0.4$ & $36.90 \pm 0.32$ & $0.02^{*}$ \\
\hline \multirow{2}{*}{$\begin{array}{l}\text { O2 saturation at the time } \\
\text { of admission }\end{array}$} & $\geq 92 \%$ & $61(89.7)$ & $18(62.1)$ & $79(81.4)$ & \multirow{2}{*}{$0.002^{*}$} \\
\hline & $<92 \%$ & $7(10.3)$ & 11(37.9) & 18(18.6) & \\
\hline \multirow{2}{*}{$\begin{array}{l}\text { Glasgow coma scale at } \\
\text { the time of admission }\end{array}$} & $14-15$ & $65(95.6)$ & $20(69.0)$ & $85(87.6)$ & \multirow{2}{*}{$0.001^{*}$} \\
\hline & $<14$ & $3(4.4)$ & $9(31.0)$ & 12(12.4) & \\
\hline \multirow{2}{*}{$\begin{array}{l}\text { Level of consciousness at } \\
\text { the time of admission }\end{array}$} & Conscious & $62(91.2)$ & $14(48.3)$ & $76(78.4)$ & \multirow{2}{*}{$<0.001^{*}$} \\
\hline & Unconscious & $6(8.9)$ & 15(51.7) & $21(21.6)$ & \\
\hline \multirow{10}{*}{$\begin{array}{l}\text { Signs or symptoms at the } \\
\text { time of admission }\end{array}$} & Nausea & $44(64.7)$ & $17(58.6)$ & $61(62.9)$ & 0.65 \\
\hline & Vomiting & $34(50.0)$ & $14(48.3)$ & $48(49.5)$ & 0.99 \\
\hline & Weakness & $16(23.5)$ & $12(41.4)$ & $28(28.9)$ & 0.09 \\
\hline & Epigastric pain & $16(23.5)$ & $9(31.0)$ & $25(25.8)$ & 0.46 \\
\hline & Restlessness & $17(25.0)$ & $7(24.1)$ & $24(24.7)$ & 0.99 \\
\hline & Other & $9(13.2)$ & $8(27.6)$ & $17(17.5)$ & 0.14 \\
\hline & Not normal pupil & $1(1.5)$ & $4(13.8)$ & $5(5.2)$ & $0.03^{*}$ \\
\hline & Headache & $4(5.9)$ & $0(0)$ & $4(4.1)$ & 0.31 \\
\hline & Thirsty & $1(1.5)$ & $0(0)$ & $1(1.0)$ & 0.99 \\
\hline & Cyanosis & $0(0)$ & $1(3.4)$ & $1(1.0)$ & 0.30 \\
\hline \multirow{7}{*}{$\begin{array}{l}\text { Signs or symptoms during } \\
\text { the hospitalization }\end{array}$} & Resistant acidosis & $10(14.7)$ & $17(58.6)$ & $27(27.8)$ & $<0.001^{*}$ \\
\hline & & $8(11.8)$ & $16(55.2)$ & $24(24.7)$ & $<0.001^{*}$ \\
\hline & 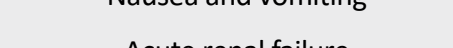 & $4(5.9)$ & $2(6.9)$ & $6(6.2)$ & 0.99 \\
\hline & Acute rendi laliure & $1(1.5)$ & $4(13.8)$ & $5(5.2)$ & $0.03^{*}$ \\
\hline & 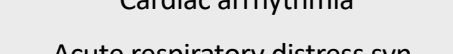 & $1(1.5)$ & $3(10.3)$ & $4(4.1)$ & 0.08 \\
\hline & drome (ARDS) & 0(00 & $1(3.4)$ & $1(1.0)$ & 0.30 \\
\hline & Multiorgan failure & $0(0)$ & $0(0)$ & $0(0)$ & - \\
\hline Serum sodium status at & Normal & $64(94.1)$ & $26(89.7)$ & $90(92.8)$ & \multirow{2}{*}{0.67} \\
\hline the time of admission & Hypernatremia & $4(5.9)$ & $3(10.3)$ & $7(7.2)$ & \\
\hline \multirow{3}{*}{$\begin{array}{l}\text { Serum potassium status } \\
\text { at the time of admission }\end{array}$} & Normal & $49(72.1)$ & $18(62.1)$ & $67(69.1)$ & \multirow{3}{*}{0.22} \\
\hline & Hypokalemia & $16(23.5)$ & 11(37.9) & $27(27.8)$ & \\
\hline & Hyperkalemia & $3(4.4)$ & $0(0)$ & $3(3.1)$ & \\
\hline \multicolumn{2}{|c|}{$\mathrm{PH}$ at the time of admission } & $7.4 \pm 0.1$ & $7.2 \pm 0.2$ & $7.3 \pm 0.1$ & $<0.001^{*}$ \\
\hline \multicolumn{2}{|c|}{$\mathrm{HCO}_{3}(\mathrm{mEq} / \mathrm{L})$ at the time of admission } & $20.3 \pm 5.5$ & $14.8 \pm 3.6$ & $18.9 \pm 5.6$ & $<0.001^{*}$ \\
\hline
\end{tabular}

* Statistically significant; SD: Standard Deviation 
Table 4. Patients' treatments

\begin{tabular}{|c|c|c|c|c|}
\hline \multirow{2}{*}{ Treatment } & \multicolumn{3}{|c|}{ Mean $\pm S D /$ No.(\%) } & \multirow{2}{*}{$\mathbf{P}$} \\
\hline & Survivor $(n=68)$ & Non-survivor(n=29) & Total $(n=97)$ & \\
\hline Castor oil & $46(67.6)$ & $18(62.1)$ & $64(66.0)$ & 0.64 \\
\hline N-Acetyl Cysteine (NAC) & $40(58.8)$ & 15(51.7) & $55(56.7)$ & 0.66 \\
\hline Magnesium sulfate $\left(\mathrm{MgSO}_{4}\right)$ & $33(48.5)$ & $18(62.1)$ & $51(52.6)$ & 0.27 \\
\hline Calcium gluconate & $34(50.0)$ & 15(51.7) & $49(50.5)$ & 0.99 \\
\hline Sodium bicarbonate $\left(\mathrm{NaHCO}_{3}\right)$ & $24(35.3)$ & $19(65.5)$ & $43(44.3)$ & $0.008^{*}$ \\
\hline Docosahexaenoic Acid (DHA) & $21(30.9)$ & $15(51.7)$ & $36(37.1)$ & 0.07 \\
\hline Hydrocortisol & $29(42.6)$ & $7(24.1)$ & $36(37.1)$ & 0.11 \\
\hline Vitamin E & 21(30.9) & 11(37.9) & $32(33.0)$ & 0.64 \\
\hline Norepinephrine & $10(14.7)$ & $8(27.6)$ & $18(18.4)$ & 0.16 \\
\hline Hydroxyethyl starch (Voluven) & $7(10.3)$ & $6(20.7)$ & 13(13.4) & 0.20 \\
\hline Epinephrine & $1(1.5)$ & $7(24.1)$ & $8(8.2)$ & $0.001^{*}$ \\
\hline Dopamine & $2(2.9)$ & $5(17.2)$ & $7(7.2)$ & $0.02^{*}$ \\
\hline Dexamethasone & $3(4.4)$ & $3(10.3)$ & $6(6.2)$ & 0.36 \\
\hline Dobutamine & $1(1.2)$ & $2(6.9)$ & $3(3.1)$ & 0.21 \\
\hline Vitamin C & $2(2.9)$ & $1(3.4)$ & $3(3.1)$ & 0.99 \\
\hline Atropine & $0(0)$ & $3(10.3)$ & $3(3.1)$ & $0.03^{*}$ \\
\hline Ondansetron & $2(2.9)$ & $0(0)$ & $2(2.1)$ & 0.99 \\
\hline Naloxone & $0(0)$ & $1(3.4)$ & $1(1.0)$ & 0.30 \\
\hline Livergol & $1(1.5)$ & $0(0)$ & $1(1.0)$ & 0.99 \\
\hline
\end{tabular}

hand, a deeper emotional bond among villagers might explain this observation. Nonetheless, migration from rural to urban areas and the larger population of cities should not be neglected.

In the present study, it was also found that most patients poisoned with ALP were literate. Montazer et al. reported that the incidence of poisoning was two times higher in patients with education under diploma than those with a bachelor's or higher degree, which could be due to the greater awareness of educated people about the agonizing death caused by ALP [27].

We found that all patients $(100 \%)$ in this study had committed suicide attempts, similar to previous studies $[3,4,35,43]$. Hosseinian et al. reported that suicidal intention was observed in $97 \%$ of the ALP poisoned patients. Also, Etemadi-Aleagha et al. and Taghaddosi Nejad et al. reported these rates as $85 \%$ and $97 \%$, respectively $[14,44]$. In the present study, $86.6 \%$ of poisoning cases were due to using ALP tablet. Also, Yaghoobi and Shafipour reported that $62 \%$ of patients with ALP poisoning used the tablet form while the rest consumed the powder form [42].

Khodabandeh et al. stated that the Mean \pm SD number of tablets consumed was $2.0 \pm 0.5$ tablets [34]. This number was reported $1.7 \pm 1.0$ and $2.6 \pm 1.9$, respectively, in survived and non-survived patients in the Navabi et al.'s study [3]. Rahbar Taramsary et al. also found 1 (in $41.2 \%$ of cases) is the most common number of consumed tablets [29]. In the present study, more than $70 \%$ of ALP 
Table 5. Univariate logistic regression analysis for factors related to in-hospital mortality of patients with aluminum phosphide poisoning

\begin{tabular}{|c|c|c|c|c|c|c|}
\hline Variables & & B & SE & Odds Ratio (OR) & 95\% Confidence Interval & $\mathbf{P}$ \\
\hline \multirow{2}{*}{ Gender } & Female & - & - & 1.0 (Reference) & - & \multirow{2}{*}{$0.03 *$} \\
\hline & Male & 1.02 & 0.48 & 2.78 & $0.08-7.15$ & \\
\hline \multirow{2}{*}{ Education } & Literate & - & - & 1.0 (Reference) & - & \multirow{2}{*}{$0.005^{*}$} \\
\hline & Illiterate & 2.35 & 0.84 & 10.50 & $2.03-54.34$ & \\
\hline \multirow{2}{*}{ Glasgow coma scale } & $14-15$ & - & - & 1.0 (Reference) & - & \multirow{2}{*}{$0.001^{*}$} \\
\hline & $<14$ & 2.28 & 0.71 & 9.75 & $2.41-39.52$ & \\
\hline \multirow{2}{*}{ Not normal pupil } & No & - & - & 1.0 (Reference) & - & \multirow{2}{*}{$0.04 *$} \\
\hline & Yes & 2.37 & 1.14 & 10.72 & $1.14-100.59$ & \\
\hline \multirow{2}{*}{ Resistant acidosis } & No & - & - & 1.0 (Reference) & - & \multirow{2}{*}{$<0.001^{*}$} \\
\hline & Yes & -2.11 & 0.51 & 8.22 & $3.03-22.30$ & \\
\hline \multirow{2}{*}{ Hypotension } & No & - & - & 1.0 (Reference) & - & \multirow{2}{*}{$<0.001^{*}$} \\
\hline & Yes & 2.22 & 0.53 & 9.23 & $3.27-26.09$ & \\
\hline \multirow{2}{*}{ Acute renal failure } & & - & - & 1.0 (Reference) & - & \multirow{2}{*}{$0.04 *$} \\
\hline & & 2.37 & 1.14 & 10.72 & $1.14-100.59$ & \\
\hline \multirow{2}{*}{ Sodium bicarbonate $\left(\mathrm{NaHCO}_{3}\right)$} & No & - & - & 1.0 (Reference) & - & \multirow{2}{*}{$0.07^{*}$} \\
\hline & Yes & 1.25 & 0.47 & 3.48 & $1.40-8.68$ & \\
\hline Age & & 0.05 & 0.02 & 1.05 & $1.01-1.09$ & $0.01^{*}$ \\
\hline Systolic blood pressure (mmHg) & & -0.06 & 0.02 & 0.94 & $0.92-0.97$ & $<0.001^{*}$ \\
\hline Diastolic blood pressure $(\mathrm{mmHg})$ & & -0.07 & 0.02 & 0.93 & $0.90-0.97$ & $<0.001^{*}$ \\
\hline Respiratory rate (per minute) & & 0.26 & 0.10 & 1.29 & $1.06-1.58$ & $0.01^{*}$ \\
\hline Temperature $\left({ }^{\circ} \mathrm{C}\right)$ & & -2.51 & 0.90 & 0.08 & $0.01-0.47$ & $0.005^{*}$ \\
\hline $\mathrm{HCO}_{3}(\mathrm{mEq} / \mathrm{L})$ & & -0.21 & 0.06 & 0.81 & $0.73-0.91$ & $<0.001^{*}$ \\
\hline
\end{tabular}

poisoning cases occurred in the evening and night, and no significant difference was observed between different seasons. Montazer et al. also noticed that the peak of ALP poisoning was in autumn and the evening; however, this difference was not statistically significant. They stated that this finding is justified as autumn is the season for the collection and storage of this substance, leading to its higher abuse at this time [27]. Nevertheless, Shadnia et al. reported that spring and winter were the most common seasons of ALP poisoning [32].

Similar to the findings of studies by Etemadi-Aleagha et al. [14], Montazer et al. [27], and Hosseinian et al. [33], we found that nausea and vomiting were the most common symptoms at the time of admission. Nevertheless, the two groups of survivors and non-survivors had only a statistically significant difference in the pres- ence of abnormal pupils, which was higher among the non-survivors. Other clinical symptoms were similar between the two groups. In Rahbar Taramsary et al.'s study, $78.4 \%$ of patients experienced gastrointestinal symptoms [29]. Khodabandeh et al. reported the most common symptoms as vomiting (96.4\%) and restlessness $(36.9 \%)$. They stated that symptoms such as nausea, vomiting, epigastric pain, and shock were evidence of severe reactive hypotension [34].

In the present study, there were statistically significant differences between the survivor and non-survivors groups regarding vital signs such as SBP, DBP, RR, body temperature, $\mathrm{O}_{2}$ saturation, GCS, and the level of consciousness. Also, it was demonstrated that body temperature was a predictor of mortality, which has not been reported in previous studies. In the study of Aziz 
Table 6. Multivariate logistic regression analysis for factors related to in-hospital mortality of patients with aluminum phosphide poisoning

\begin{tabular}{cccccc}
\hline Variables & B & SE & Odds Ratio (OR) & 95\% Confidence Interval & P-Value \\
\hline Age & 0.12 & 0.04 & 1.12 & $1.03-1.22$ & $0.009^{*}$ \\
\hline Education (being illiterate) & 3.69 & 1.97 & 39.95 & $0.85-11887.59$ & 0.6 \\
\hline Temperature $\left({ }^{\circ} \mathrm{C}\right)$ & -3.76 & 1.55 & 0.02 & $0.01-0.48$ & $0.02^{*}$ \\
\hline Resistant acidosis (yes) & 4.35 & 1.39 & 77.10 & $5.05-1176.86$ & $0.002^{*}$ \\
\hline Sodium bicarbonate $\left(\mathrm{NaHCO}_{3}\right.$ ) (yes) & 2.51 & 1.17 & 12.35 & $1.25-122.10$ & $0.03^{*}$ \\
\hline
\end{tabular}

* Statistically significant

Medical Toxicology \& Forensic Medicine

and Husain, tachycardia was seen in $68 \%$ of the patients [33]. Khodabandeh et al. noted that $76.6 \%$ of patients had tachycardia at the time of admission, and the most common disorders during hospitalization were bradycardia, ventricular tachycardia, and atrial fibrillation [34]. In another study by Montazer et al., half of the patients had normal arterial $\mathrm{O}_{2}$ saturation at the time of admission [27]. Furthermore, Navabi et al. described blood pressure as a predictor of mortality so that $91.7 \%$ of patients with shock finally died [3]. Rahbar Taramsary et al. reported that the mortality rate was $92.1 \%$ in patients with $\mathrm{SBP}<90 \mathrm{mmHg}$ and $14.3 \%$ in patients with SBP> $90 \mathrm{mmHg}$ [29]. Finally, Taghadosinejad et al. stated that shock was one of the most important complications of ALP poisoning, associated with high mortality [39].

In our study, sodium and potassium were within the normal range in most patients, with no statistically significant difference between survivors and non-survivors. In the study of Montazer et al., the most common electrolyte disturbances among patients were hyponatremia and hypokalemia, and more than half of the patients had normal laboratory findings at the time of admission [27]. Rahbar Taramsary et al. reported that $92 \%$ of patients had normal sodium levels [29]. Overall, electrolyte disturbances can occur in severe ALP poisoning. Hypokalemia is caused by metabolic acidosis, kidney failure, and hypermagnesemia. On the other hand, a fall in insulin level reduces the permeability of muscle cells to glucose, leading to water leakage from muscles and, subsequently hyponatremia [18].

We demonstrated that complications such as resistant acidosis, hypotension, and ARF were more common in non-survived patients. Also, resistant acidosis was determined as a prognostic factor for in-hospital mortality in patients with ALP poisoning. Moreover, 29.9\% of patients were admitted to the ICU with no statistically significant difference between survivors and non- survivors. In a study by Nosrati et al., all patients were admitted to the ICU [30]. Khodabandeh et al. reported cardiac arrhythmias, drug-resistant hypotension, acidosis, and ARF as the most common causes of death in patients with ALP poisoning, respectively [34]. In another study by Montazer et al., 7.69\% of patients developed the complications of ALP poisoning [27]. Hosseinian et al. observed dysrhythmia in $45 \%$ of patients [31]. Aziz and Husain reported arrhythmia in $71 \%$ of patients. In a recent report, cardiac arrhythmia, hypotension, ARF, hepatic congestion, and Disseminated Intravascular Coagulation (DIC) were the most common complications of ALP poisoning and the most common causes of death in patients were cardiogenic shock and toxic myocarditis [33]. Cardiovascular collapse occurs due to the direct effect of phosphine gas on cardiac cells, fluid loss, and subsequently fatal arrhythmias and drug-resistant hypotension. Adult ARDS, ARF, and severe hypoxia are among the delayed complications of ALP poisoning, which have a poor prognosis and occur due to direct cell destruction by phosphine and secondary to severe acidosis and cardiovascular failure [34].

ALP poisoning has no specific antidote; therefore, its management is supportive. Early diagnosis using appropriate predictors of mortality may provide good care and prognosis. Castor oil, NAC, and magnesium sulfate $\left(\mathrm{MgSO}_{4}\right)$ were the most frequent treatment in patients with ALP poisoning. Large amounts of sodium bicarbonate $\left(\mathrm{NaHCO}_{3}\right)$ are recommended for correction of acidosis in ALP poisoned patients, but there is some controversy about its effectiveness [12, 13, 30, 45]. We found that taking sodium bicarbonate $\left(\mathrm{NaHCO}_{3}\right)$ in ALP poisoned patients is one of the main prognostic factors for in-hospital mortality. However, the wide 95\% CI showed a small sample size for determining this factor as a prognostic factor, hence larger studies in the design of controlled trials are recommended. 
In recent years, many prognostic factors for ALP poisoning have been used to evaluate the severity of a patient's clinical conditions. Navabi et al. found that blood pressure, blood $\mathrm{pH}$, and time elapsed from consumption to treatment were the main prognostic variables of inhospital mortality in patients with ALP poisoning. They stated that blood pressure alone might predict about $60 \%$ of mortality in these patients. Furthermore, $71.5 \%$ and $77.3 \%$ of mortality rates were predicted by using combinations of 2 (blood pressure and blood $\mathrm{pH}$ ) and 3 (blood pressure, blood $\mathrm{pH}$, and time elapsed from consumption to treatment) variables, respectively [3]. Moreover, Shadnia et al. reported arterial blood $\mathrm{PH}$ as a prognostic factor for mortality [32]. In another study, they found Systolic Blood Pressure (SBP), Glasgow Coma Scale (GCS), hematocrit, white blood count, level of blood sugar, Blood Urea Nitrogen (BUN), Simplified Acute Physiology Score (SAPS II) score, blood PH, Electrocardiograph (ECG) and the number of ALP ingested tablets as effective for predicting the patients' outcome [2]. SBP and ECG changes were determined as predictors in Soltaninejad et al.'s study [46]. Farzaneh et al. concluded that $\mathrm{SBP}$ of $<92.5 \mathrm{mmHg}, \mathrm{HCO}_{3}-<12.9 \mathrm{mEq} / \mathrm{L}$, urinary output $<1725 \mathrm{~mL} /$ day, and GCS $<14.5$ were predictors of mortality in ALP poisoned patients [21].

Based on the study of Rahbar Taramsary et al., the mortality rate of ALP poisoning had a statistically significant relationship with the time between the incidence of poisoning and the patient's arrival at the medical center, the number of consumed tablets, $\mathrm{SBP}, \mathrm{pH}, \mathrm{HCO}_{3}$ concentration, and $\mathrm{O}_{2}$ saturation. In this regard, consuming more than half a rice tablet, blood pressure lower than 90 $\mathrm{mmHg}$, blood $\mathrm{pH}<7.2, \mathrm{HCO}_{3}$ level $<15.0 \mathrm{mEq} / \mathrm{L}$ and a delay of more than 30 minutes from the consumption to treatment could increase the mortality rate [29]. In the current study, we found that higher age, higher body temperature, resistant acidosis, and taking sodium bicarbonate $\left(\mathrm{NaHCO}_{3}\right)$ were the primary critical prognostic variables of in-hospital mortality in patients with ALP poisoning. Therefore, these factors should be mentioned to physicians in managing patients with ALP poisoning to reduce in-hospital mortality.

\section{Conclusion}

The in-hospital mortality rate in patients with ALP poisoning was $29.9 \%$ in this study. The results showed that age, being illiterate, body temperature, resistant acidosis, and taking sodium bicarbonate were the main prognostic factl mortality in patients with ALP poisoning. The results of the study might help physicians for better patients management. Informing public population and particularly the youth about the threats of toxins, especially ALP, and their painful death, identifying and resolving familial and social problems, paying particular attention to young people and their issues, and not granting easy and cheap access to rice tablets in stores should be considered by health policymakers to prevent ALP-related poisoning and mortality.

One of the strengths of this study is that the sample size was larger than most of the similar studies. Furthermore, we determined the prognostic factors for in-hospital mortality. The main limitation of this study was its retrospective method and being conducted in a single center. Also, some patients' medical files were excluded due to uncompleted data records, and some patients' medical files were missing. For example, we could not analyze some laboratory, ECG, and radiological findings in detail. Also, the diagnosis of ALP poisoning was not confirmed by the silver nitrate test. Therefore, multicenter, prospective studies can provide more information for physicians and policymakers. Establishing a registry system for patients with poisoning can provide more information.

\section{Ethical Considerations}

\section{Compliance with ethical guidelines}

The current study was conducted following the Declaration of Helsinki, and it was approved by the ViceChancellor of Research and Technology, as well as the local Ethics Committee of Shiraz University of Medical Sciences (IR.sums.med.rec.1397.472). To consider the ethical issue, the collected data were not revealed to anyone except for the researchers; hence, patients' names were kept confidential.

\section{Funding}

The current study was financially supported by the Vice-Chancellor of Research and Technology of Shiraz University of Medical Sciences (Grant No.: 15575).

\section{Author's contributions}

Conceptualizationt and Methodology: Mehdi Alibeigi, Razieh Sadat Mousavi-Roknabadi, Najmeh Ahmadzadeh Goli, Faramarz Farahmand, and Mehrdad Sharif; Searching the related articles: Mehdi Alibeigi and Razieh Sadat Mousavi-Roknabadi; Acquisition of data: Mehdi Alibeigi and Najmeh Ahmadzadeh Goli; Data analysis: Razieh Sadat Mousavi-Roknabadi; Drafting of the manuscript: Mehdi Alibeigi, Razieh Sadat MousaviRoknabadi, Najmeh Ahmadzadeh Goli, and Faramarz 
Farahmand, Mehrdad Sharifi; Critical revision of the manuscript for important intellectual content: Mehdi Alibeigi, Razieh Sadat Mousavi-Roknabadi, Najmeh Ahmadzadeh Goli, Faramarz Farahmand, and Mehrdad Sharifi; Final confirmation: Mehdi Alibeigi, Razieh Sadat Mousavi-Roknabadi, Najmeh Ahmadzadeh Goli, Faramarz Farahmand, and Mehrdad Sharifi.

\section{Conflict of interest}

The authors declared no conflict of interest.

\section{Acknowledgments}

The study was approved and financially supported by Shiraz University of Medical Sciences (Grant No.: 15575) and the local Ethics Committee of Shiraz University of Medical Sciences (Code: IR.sums.med. rec.1397.472).

\section{References}

[1] Shokrzadeh M, Zarei H, Jalilian J, Badeli A, Ebrahimi Falahtalab F, Shayeste Y. [A comparison of mortality rate caused by Aluminum Phosphide with other poisonings in Golestan Province, Iran, 2010 - 2016 (Persian)]. Med J Mashhad Univ Med Sci. 2017; 60(5):689-90. https://mjms.mums. ac.ir/article_10453.html

[2] Shadnia S, Mehrpour O, Soltaninejad K. A simplified acute physiology score in the prediction of acute aluminum phosphide poisoning outcome. Indian J Med Sci. 2010; 64(12):532-9. [PMID]

[3] Navabi SM, Navabi J, Aghaei A, Shaahmadi Z, Heydari R. Mortality from aluminum phosphide poisoning in Kermanshah Province, Iran: Characteristics and predictive factors. Epidemiol Health. 2018; 40:e2018022. [DOI:10.4178/epih. e2018022] [PMID] [PMCID]

[4] Bogle RG, Theron P, Brooks P, Dargan PI, Redhead J. Aluminium phosphide poisoning. Emerg Med J. 2006; 23(1):e3. [DOI:10.1136/emj.2004.015941] [PMID] [PMCID]

[5] Shokrzadeh M, Alizadeh A, Veisi F, Nasri-Nasrabadi N. [The mortality rate of aluminum phosphide poisoning; a comparison with other poisonings recorded in Mazandaran Department of Forensic Medicine, Iran, 2009-2011 (Persian)]. J Isfahan Med School. 2015; 33(322):114-24. http://jims.mui. ac.ir/index.php/jims/article/view/4100

[6] Shadnia S, Soltaninejad K, Hassanian-Moghadam H, Sadeghi A, Rahimzadeh H, Zamani N, et al. Methemoglobinemia in aluminum phosphide poisoning. Hum Exp Toxicol. 2011; 30(3):250-3. [DOI:10.1177/0960327110384287] [PMID]

[7] Mehrpour O, Alfred S, Shadnia S, Keyler DE, Soltaninejad K, Chalaki N, et al. Hyperglycemia in acute aluminum phosphide poisoning as a potential prognostic factor. Hum Exp Toxicol. 2008; 27(7):591-5. [DOI:10.1177/0960327108096382] [PMID]
[8] Brautbar N, Howard J. Phosphine toxicity: Report of two cases and review of the literature. Toxicol Ind Health. 2002; 18(2):71-5. [DOI:10.1191/0748233702th133oa] [PMID]

[9] Kaushik RM, Kaushik R, Mahajan SK. Subendocardial infarction in a young survivor of aluminium phosphide poisoning. Hum Exp Toxicol. 2007; 26(5):457-60. [DOI:10.1177/0960327107074618] [PMID]

[10] Taheri S K, Afzali S, Khaled Naghshbandi M, Norouzi F, Mohammadi N. [Report of two cases of accidental poisoning due to "rice tablet" misuse (Persian)]. Iran J Forensic Med. 2011; 17(3):199-203. http://sjfm.ir/article-1-470-fa.html

[11] Mehrpour O, Amouzeshi A, Dadpour B, Oghabian Z, Zamani N, Amini $S$, et al. Successful treatment of cardiogenic shock with an intraaortic balloon pump following aluminium phosphide poisoning. Arh Hig Rada Toksikol. 2014; 65(1):121-6. [DOI:10.2478/10004-1254-65-2014-2393] [PMID]

[12] Hashemi-Domeneh B, Zamani N, Hassanian-Moghaddam $\mathrm{H}$, Rahimi M, Shadnia S, Erfantalab P, et al. A review of aluminium phosphide poisoning and a flowchart to treat it. Arh Hig Rada Toksikol. 2016; 67(3):183-93. [DOI:10.1515/aiht2016-67-2784] [PMID]

[13] Marashi SM, Nasri-Nasrabadi Z. Can sodium bicarbonate really help in treating metabolic acidosis caused by aluminium phosphide poisoning? Arh Hig Rada Toksikol. 2015; 66(1):83-4. [DOI:10.1515/aiht-2015-66-2637] [PMID]

[14] Etemadi-Aleagha A, Akhgari M, Iravani FS. Aluminum phosphide poisoning-related deaths in Tehran, Iran, 2006 to 2013. Medicine (Baltimore). 2015; 94(38):e1637. [DOI:10.1097/ MD.0000000000001637] [PMID] [PMCID]

[15] Sharma T, Sharma A, Kapoor D. Profile of aluminum phosphide poisoning in a tertiary care institute in the subHimalayan region. J Family Med Prim Care. 2018; 7(3):581-3. [DOI:10.4103/jfmpc.jfmpc_231_17] [PMID] [PMCID]

[16] Alnasser S, Hussain SM, Kirdi TS, Ahmed A. Aluminum phosphide poisoning in Saudi Arabia over a nine-year period. Ann Saudi Med. 2018; 38(4):277-83. [DOI:10.5144/02564947.2018.277] [PMID] [PMCID]

[17] Agrawal VK, Bansal A, Singh RK, Kumawat BL, Mahajan P. Aluminum phosphide poisoning: Possible role of supportive measures in the absence of specific antidote. Indian J Crit Care Med. 2015; 19(2):109-12. [DOI:10.4103/09725229.151019] [PMID] [PMCID]

[18] Mehrpour O, Jafarzadeh M, Abdollahi M. A systematic review of aluminium phosphide poisoning. Arh Hig Rada Toksikol. 2012; 63(1):61-73. [DOI:10.2478/10004-1254-632012-2182] [PMID]

[19] Sinha N. Aluminium phosphide poisoning. Indian J Med Specialities. 2018; 9(3):167-70. [DOI:10.1016/j.injms.2018.06.006]

[20] Murali R, Bhalla A, Singh D, Singh S. Acute pesticide poisoning: 15 years' experience of a large North-West Indian hospital. Clin Toxicol (Phila). 2009; 47(1):35-8. [PMID]

[21] Farzaneh E, Ghobadi H, Akbarifard M, Nakhaee S, Amirabadizadeh A, Akhavanakbari G, et al. Prognostic factors in acute aluminium phosphide poisoning: A risk-prediction nomogram approach. Basic Clin Pharmacol Toxicol. 2018; 123(3):347-55. [DOI:10.1111/bcpt.13005] [PMID] 
[22] Kordrostami R, Akhgari M, Ameri M, Ghadipasha M, Aghakhani K. Forensic toxicology analysis of self-poisoning suicidal deaths in Tehran, Iran; trends between 20112015. Daru. 2017; 25(1):15. [DOI:10.1186/s40199-017-0181-1] [PMID] [PMCID]

[23] Walker HK, Hall WD, Hurst JW, editors. Clinical methods: The history, physical, and laboratory examinations. 3rd ed. Boston: Butterworths; 1990. [PMID]

[24] Sharma S, Hashmi MF, Bhattacharya PT. Hypotension. In: StatPearls [Internet]. Treasure Island (FL): StatPearls Publishing; 2021. [PMID]

[25] Alizadeh A, Rakhshanizadeh F. Loss of consciousness in a little traveler. Caspian J Intern Med. 2021; 12(1):103-6. [PMID]

[26] Makris K, Spanou L. Acute kidney injury: Definition, pathophysiology and clinical phenotypes. Clin Biochem Rev. 2016; 37(2):85-98. [PMID]

[27] Montazer H, Laali A, Khosravi N, Amini Ahidashti H, Rahiminezhad M, Mohamadzadeh A. [Epidemiological, clinical and laboratory features in patients poisoned with aluminum phosphide (Persian)]. J Mazandaran Univ Med Sci. 2016; 26(137):188-95. http:/ /jmums.mazums.ac.ir/article1-7716-en.html

[28] Christophers AJ, Singh S, Goddard DG, Facem AN. Dangerous bodies: A case of fatal aluminium phosphide poisoning. Med J Aust. 2002; 176(8):403 [DOI:10.5694/j.1326-5377.2002. tb04471.x]

[29] Rahbar Taramsary M, Orangpoor R, Zarkami T, Palizkar M, Mousavian S. [Survey patients poisoned with aluminum phosphide (Rice Tablet) (Persian)]. J Guilan Univ Me Sci. 2006; 14(56):42-7. http:/ /journal.gums.ac.ir/article-1-494-en.html

[30] Nosrati A, Karami M, Esmaeilnia M. Aluminum phosphide poisoning: A case series in North Iran. Asia Pac J Med Toxicol. 2013; 2(3):111-3. [DOI:10.22038/APJMT.2013.1674]

[31] Hosseinian A, Pakravan N, Rafiei A, Feyzbakhsh SM. Aluminum phosphide poisoning known as rice tablet: A common toxicity in North Iran. Indian J Med Sci. 2011; 65(4):143-50. [PMID]

[32] Shadnia S, Sasanian G, Allami P, Hosseini A, Ranjbar A, Amini-Shirazi N, et al. A retrospective 7-years study of aluminum phosphide poisoning in Tehran: Opportunities for prevention. Hum Exp Toxicol. 2009; 28(4):209-13. [DOI:10.1177/0960327108097194] [PMID]

[33] Aziz U, Husain A. Frequency of cardiac arrhythmias in patients with aluminum phosphide poisoning. Asia Pac J Med Toxicol. 2015; 4(4):147-50. [DOI:10.22038/APJMT.2015.6257]

[34] Khodabandeh F, Kahani A, Soleimani G. [The study of fatal complications of "rice tablet "poisoning (Persian)]. Iran J Forensic Med. 2014; 20(2):27-36. http:/ /sjfm.ir/article-1-584-en.html

[35] Siddaiah L, Adhyapak S, Jaydev S, Shetty G, Varghese K, Patil C, et al. Intra-aortic balloon pump in toxic myocarditis due to aluminum phosphide poisoning. J Med Toxicol. 2009; 5(2):80-3. [DOI:10.1007/BF03161093] [PMID] [PMCID]

[36] Saha JK, Azad KAK, Hossain MZ, Amin MR, Ahmed M, Ahsan HMN, et al. Aluminium phosphide poisoning cases in a tertiary care hospital. J Dhaka Med Coll. 2014; 23(1):3-6. [DOI:10.3329/jdmc.v23i1.22685]
[37] Ranga G, Dwivedi S, Agarwal M, Kumar D. Aluminium phosphide poisoning in a young adult: A suicidal cardiotoxin simulating myocardial ischaemia. J Indian Acad Clin Med. 2004; 5(4):369. https://scholar.google.com/ scholar?hl=en\&as_sdt $=0 \% 2 C 5 \& q=+2004 \& b t n G=$

[38] Fayaz A. [Evaluation of related factors in pulmonary edema and aspiration pneumonia among rice tablet poisonings (Persian]. EBNESINA. 2014; 16(1-2):72-8. http://ebnesina. ajaums.ac.ir/article-1-288-en.htm

[39] Taghadosinejad F, Behnoush B, Okazi A, Marashi S M, Mohseni K, Sadeghian M. [A study of poisoning induced shock in patients referred to Baharloo Hospital from June 2011 to June 2012 (Persian)]. Razi J Med Sci. 2014; 21(119):49-59. http://rjms.iums.ac.ir/article-1-3102-en.html

[40] Louriz M, Dendane T, Abidi K, Madani N, Abouqal R, Zeggwagh AA. Prognostic factors of acute aluminum phosphide poisoning. Indian J Med Sci. 2009; 63(6):227-34. [PMID]

[41] Ahmadi H, Soleimani A. Suicides resulting in death by poisoning among patients referred to Imam Khomeini Hospital in Kermanshah (2007-10). J Kermanshah Univ Med Sci. 2013; 17(3):e77111. https://sites.kowsarpub.com/jkums/articles/77111.html

[42] Yaghoobi Y, Shafi Poor Z. [Survey socio-demographic characteristics of adolescents attempted suicide with rice tablet in Razi Hospital in Rasht (Persian)]. J Holist Nurs Midwifery. 2007; 17(2):45-50. http://hnmj.gums.ac.ir/article1-259-en.html

[43] Shadnia S, Mehrpour O, Abdollahi M. Unintentional poisoning by phosphine released from aluminum phosphide. Hum Exp Toxicol. 2008; 27(1):87-9. [DOI:10.1177/0960327107086241] [PMID]

[44] Taghaddosinejad F, Farzaneh E, Ghazanfari-Nasrabad M, Eizadi-Mood N, Hajihosseini M, Mehrpour O. The effect of $\mathrm{N}$-acetyl cysteine (NAC) on aluminum phosphide poisoning inducing cardiovascular toxicity: A case-control study. Springerplus. 2016; 5(1):1948. [DOI:10.1186/s40064-016-36302] [PMID] [PMCID]

[45] Najafi F, Mousavi-Roknabadi RS, Pirdehghan A, Rahimian M, Nourimajalan N. The effect of n-acetylcysteine on hsCRP in patients on continues ambulatory peritoneal dialysis; A quasi-experimental study. Nephrourol Mon. 2021; 13(3):e113990. [DOI:10.5812/numonthly.113990]

[46] Soltaninejad K, Beyranvand MR, Momenzadeh SA, Shadnia $\mathrm{S}$. Electrocardiographic findings and cardiac manifestations in acute aluminum phosphide poisoning. J Forensic Leg Med. 2012; 19(5):291-3. [DOI:10.1016/j.jflm.2012.02.005] [PMID] 